\title{
Material Hilang Sirkulasi Berbahan Dasar Serat
}

\author{
Purnomosidi \\ Politeknik Energi dan Mineral Akamigas, Cepu
}

\begin{abstract}
ABSTRAK
Hilang sirkulasi merupakan masalah yang dapat terjadi pada saat operasi pemboran. Hilang sirkulasi dapat terjadi ketika fluida pemboran bertekanan bersirkulasi melewati lapisan high permeable dan ataupun lapisan rekah. Material hilang sirkulasi (LCM) ditambahkan ke dalam fluida pemboran untuk menanggulangi hilang sirkulasi, dapat berupa tipe serat, granular dan atau flaky. Bahan hilang sirkulasi tipe serat alami dipilih untuk membantu penanganan hilang sirkulasi yang timbul dengan cara membentuk mud cake, menutup zona loss dan dianggap ramah lingkungan.
\end{abstract}

Kata kunci: hilang sirkulasi, lumpur pemboran, serat alami, rekah alami, bahan hilang sirkulasi

\section{PENDAHULUAN}

Hilang sirkulasi adalah hilangnya sebagian atau seluruh volume fluida pemboran ataupun slurry semen pemboran ke dalam pori-pori suatu formasi batuan selama operasi pemboran berlangsung (Jain dkk, 2013). Kondisi ini terjadi akibat tekanan hidrostatik yang berlebihan (Kefi dkk, 2010). Pemboran dengan metode over balance akan mengakibatkan tekanan hidrostatik kolom lumpur lebih tinggi terhadap tekanan pori batuan dan dapat memicu proses hilang sirkulasi ketika rekahan mulai terbentuk (Alsaba dkk, 2014). Oleh karena itu, densitas fluida pemboran harus dipertahankan dalam ruang jendela diantara tekanan pori dan tekanan rekah batuan untuk menghindari terjadinya rekahan buatan terhadap dinding lubang bor (Kumar, dkk, 2014).

Secara umum, hilang sirkulasi terjadi pada lapisan berikut: rekah alami dan atau buatan, formasi cavernous, formasi high permeable, dan formasi tidak terkonsolidasi (Priening dkk, 2008).

Hilang sirkulasi fluida pemboran dapat terindikasi melalui adanya penurunan sebagian level volume lumpur di tanki penampung permukaan atau bahkan hilang total seluruh kolom fluida pemboran yang bersirkulasi ke dalam formasi batuan. Hilangnya fluida pemboran dalam jumlah yang signifikan dapat mengakibatkan beberapa hambatan pemboran sebagai berikut: pertambahan waktu untuk melakukan pemboran, tambahan biaya bagi fluida pemboran pengganti, serta potensi buntunya formasi produktif. Hilang sirkulasi maksimum fluida pemboran yang diijinkan untuk suatu operasi pemboran secara umum adalah sebesar $0,16 \mathrm{~m}^{3} / \mathrm{jam}$, diukur dalam mud pit di permukaan (Nayberg, 1987).

Rekahan alami dapat dijumpai selama operasi sirkulasi fluida pemboraan dilakukan. Rekahan tersebut dapat tumbuh jika tekanan 
fluida pemboran melebihi ikatan formasi batuan. Formasi rekah buatan terjadi jika tekanan hidrostatik melebihi kekuatan tensil dari batuan. Umumnya, arah rekahan merujuk ke tekanan batuan yang paling kecil.

Hilang sirkulasi dapat dikelompokkan atas seepage losses, partial losses, dan complete losses (Nayberg, 1987). Seepage losses dapat terjadi pada berbagai tipe zona formasi batuan dimana ketika bahan hilang sirkulasi (LCM) tidak optimal dalam melakukan penutupan zona hilang sirkulasi. Partial losses dapat terjadi pada lapisan batuan rekah alami, rekahan mendatar dan atau tegak, serta rekahan buatan. Di lain pihak, complete losses terjadi pada formasi dengan rekahan yang terhubung, serta rekahan buatan yang terbuka lebar (Jain, dkk, 2013; Nayberg, 1987).

Bahan hilang sirkulasi (LCM) adalah material yang digunakan untuk menanggulangi hilang sirkulasi yang terjadi selama proses pemboran berlangsung. Bahan tersebut akan membantu membentuk mud cake di zona hilang sirkulasi yang diperlukan guna mengurangi laju lumpur pemboran yang masuk kedalam zona lost circulation.

Tulisan ini bertujuan untuk memberikan ulasan terhadap penggunaan beberapa bahan hilang sirkulasi (LCM) terutama jenis serat alami serta memberikan gambaran atas manfaat yang dapat diberikan oleh LCM tersebut dalam mengatasi masalah hilang sirkulasi yang kerap dijumpai pada aplikasi pemboran.

\section{PEMBAHASAN}

\section{A. Material Hilang Sirkulasi (LCM)}

Secara umum, material hilang sirkulasi dapat digolongkan menjadi: tipe berserat, flaky, atau granular (Nayberg, 1987; White, 1956; Almagro, dkk., 2014). Material flaky meliputi cellophane, mica, cork, bonggol jagung, kulit buah tanaman kapas, dan vermiculite. Material tipe granular contohnya adalah gilsonite, butiran plastik, aspal, arang kayu, dan butiran karet juga digunakan sebagai material hilang sirkulasi. Namun, material tipe granular juga dapat berasal dari bahan alami seperti cangkang-bubuk kacang tanah. Di pihak lain, tipe material berserat kadangkala menggunakan bahan alami seperti kapas alam, serat pohon cedar, ampas tebu, batang pohon flax, dan serat tanaman beet. Serat buatan seperti serat nilon dan serat gelas juga dapat digunakan.

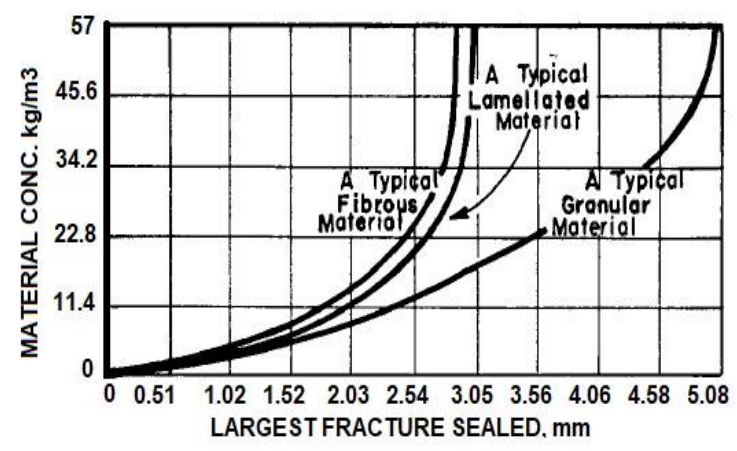

Gambar 1. Diameter rekahan yang dapat di atasi oleh material hilang sirkulasi. Ukuran diameter rekahan meningkat jika konsentrasi material hilang sirkulasi ditingkatkan (Annis dan Smith, 1996).

Gambar 1 memperlihatkan kemampuan material hilang sirkulasi tipe berserat, granular, dan flaky menanggulangi rekahan (Annis dan Smith, 1996). Penambahan material hilang sirkulasi kedalam fluida pemboran membantu mengurangi hilangnya fluida tersebut dalam proses sirkulasi dengan cara membangun mud cake di lubang bor yang permeabel untuk mengurangi invasi filtrate dan atau sebagian volume fluida pemboran kedalam rekahan dan pori-pori formasi batuan berdimensi besar.

Material berserat bekerja baik untuk menutup zona rekahan alami (Droger, dkk., 2014) dimana umumnya zona tersebut tidak mempunyai data besaran dimensi rekahannya 
(Jain, dkk., 2013).

Efektivitas material berserat dalam pencegahan hilang sirkulasi pada rekahan yang berdimensi besar telah diamati oleh berbagai peneliti. Menurut White (1956), material berserat kasar (coarse) mampu menyumbat rekahan dengan lebar 3,2 $\mathrm{mm}$ serta diameter rekah $0,5 \mathrm{~mm}$ untuk serat halus. Peningkatan konsentrasi serat kedalam fluida pemboran akan menurunkan hilang sirkulasi yang terjadi.

Material berserat harus dicampur dengan baik kedalam fluida pemboran agar dapat memberikan kemampuan penyumbatan yang optimal dengan cara membangun pondasi dasar bagi mud cake yang berguna sebagai media tapisan infiltrasi fluida pemboran kedalam zona rekahan (Kefi, dkk., 2010).

Mekanisme penyekatan celah rekahan oleh material berserat telah digambarkan oleh Silent (1936) dan Nayberg (1987). Efektivitas material berserat dalam memerangkap partikel padatan lumpur pemboran dan membentuk mud cake lebih dipengaruhi oleh diameter seratnya. Demikian pula halnya dengan serat buatan (Silent, 1936). Serat buatan mempunyai kemampuan untuk terdispersi kedalam lumpur pemboran dan mengikat partikel padatan kedalam pori-pori seratnya. Hal tersebut karena serat buatan telah mengalami uji kekuatan tarik dan tekan di laboratorium agar dapat efektif digunakan di lapangan.

Jain, dkk., (2013) berpendapat bahwa keberadaan serat di dalam lumpur pemboran akan meningkatkan efektivitas proses remediasi terhadap zona hilang sirkulasi. Lebih lanjut, menurut mereka, serat buatan dalam lumpur pemboran akan terdispersi dan menutup celah rekahan dengan cara membangun jalinan serat sebagai penghalang masuknya partikel lumpur pemboran dan juga pondasi mud cake agar tidak tergerus oleh sirkulasi lumpur pemboran tersebut.

Material serat buatan yang dibuat dalam bentuk pil mampu terdispersi ke dalam lumpur pemboran dan memitigasi hilang sirkulasi yang diakibatkan oleh celah rekahan dengan diameter kurang dari $5 \mathrm{~mm}$ (Jain, dkk., 2013). Diameter rekahan tersebut umum diketemukan selama proses pemboran sebagai rekahan alami (Almagro, dkk., 2014).

Penggunaan lebih dari 1 jenis material LCM akan memberikan kemampuan sumbat rekahan yang lebih baik (Priening dkk, 2008; Jain, dkk, 2013). Hal tersebut digambarkan oleh penulis dengan cara pencampuran serat buatan terhadap LCM jenis granular ke dalam suspensi bentonite. Terdapat pengurangan volume filtrate yang signifikan atas percobaan tersebut.

Faktor lain yang turut mempengaruhi kemampuan material berserat dalam lumpur pemboran adalah tingkat kebasahan (wettabilitas) yang dimiliki oleh material tersebut. Penyekatan akan terjadi ketika lumpur pemboran berbahan dasar air bercampur serat dengan densitas $1,398 \mathrm{~kg} / \mathrm{m}^{3}$ diinjeksi melewati celah buatan yang dipasang pada peralatan filter press, baik kondisi serat kering ataupun dibasahi oleh minyak. Sebaliknya, penyekatan gagal dilakukan oleh material serat tersebut ketika lumpur pemboran diganti dengan tipe lumpur bor tidak berbahan dasar air (Kulkarni, dkk., 2012).

Droger, dkk., (2014) mempelajari kerusakan material hilang sirkulasi tipe serat buatan. Mereka mengunakan campuran fluida dengan serat buatan sebagai material injeksi kedalam celah buatan. Pengamatan tekanan akibat kebuntuan celah buatan tersebut dilakukan dengan menerapkan perubahan waktu dan temperatur. Studi menunjukkan bahwa tekanan yang terjadi dalam tabung injeksi akan menurun seiring dengan penambahan waktu 
sirkulasi dan adanya kenaikan temperatur.

Meskipun serat buatan efektif digunakan untuk mengatasi hilang sirkulasi, namun terkadang material tersebut tidak dapat terdegradasi secara alami yang berakibat dalam jangka panjang berpotensi menurunkan permeabilitas reservoir (Droger, dkk., 2014). Oleh karena itu, serat alami yang memiliki kemampuan terdegradasi secara organik dapat digunakan sebagai material pengganti untuk hilang sirkulasi, memberikan solusi, baik untuk penyumbatan zona rekahan secara efektif dan juga bersifat tidak beracun dan dapat terdegradasi alami (Hossain dan Wajheeuddin, 2016).

\section{B. LCM berbasis serat alami}

Beberapa penelitian telah mengungkap penggunaan material alami untuk digunakan sebagai material hilang sirkulasi. Penambahan 3,175 kg serat kulit kayu untuk tiap 164-liter suspensi bentonite mampu menyekat kertas saring dalam percobaan uji tekan API dan mengurangi filtrat sebesar 11,5\% (Nestle, 1948).

Serat ampas tebu mampu untuk menyekat rekah buatan dengan diameter 0,04 -inch untuk konsentrasi 4,5 $\mathrm{kg}$ setiap 164-liter lumpur pemboran (Lummus dkk., 1971).

Pada era tahun 1950 dan 1960, Weyerhaeuser memproduksi serat kayu yang digunakan sebagai material hilang sirkulasi. Produk disebut dengan "silvacel 164" terdiri atas serat kayu dan serpihan kulit kayu. Serat kayu tersebut dibuat dengan cara memilah potongan kayu menjadi serat terpisah dengan berbagai ukuran. Serat dan serpih kayu tersebut kemudian dicampur sehingga merupakan material hilang sirkulasi dengan ukuran dan bentuk yang beragam. Material hilang sirkulasi tersebut mampu menyekat dengan baik dalam konsentrasi 599,2 hingga 1198,4 kg/m³ lumpur pemboran (Caskey, 1984).

Sebagai sumber material yang berasal dari alam, padi juga dianggap dapat berfungsi sebagai material hilang sirkulasi (Burts, 1997; Okon, dkk., 2014). Bagian yang dimanfaatkan adalah sekam padi, batang, dan dedak dengan ukuran antara 65 US mesh sampai dengan 85 US mesh dan dengan konsentrasi antara 75 persen hingga $90 \%$. Komposisi tersebut akan menciptakan hamparan jaringan serat sementara partikel butirannya akan mengisi ruangan kosong diantara hamparan serat yang sudah terjalin tersebut.

Serat kelapa diperoleh dari sabut kelapa yang memiliki kekuatan mekanis dan mudah dicampur dengan lumpur pemboran (MacQuoid dkk., 2004). Lebih lanjut, serabut kelapa mudah disirkulasi bersamaan dengan lumpur pemboran tanpa mengalami hambatan. Akan tetapi, studi ini tidak mencantumkan besaran kekuatan mekanis serabut kelapa tersebut.

Bahan material alami lain yang dapat digunakan sebagai material hilang sirkulasi adalah rumput. Serat rumput mengandung unsur kalsium, kalium dan klorin yang dapat digunakan sebagai aditif dalam lumpur pemboran. Selain itu, kadar $\mathrm{pH}$ suspensi bentonite yang dicampur dengan serat tersebut akan mengalami penurunan seiring dengan waktu pengamatan (Hossain dan Wajheeuddin, 2016). Hal ini akan memberikan manfaat tambahan berupa kestabilan $\mathrm{pH}$ lumpur pemboran yang sedang bersirkulasi.

Lebih lanjut, kurva konsistensi atas suspensi bentonit dengan rumput berbagai ukuran dan konsentrasi dikonfirmasi sesuai dengan model Bingham plastis dimana shear stress akan menurun saat shear rate mengalami peningkatan sedangkan viskositas plastis cenderung konstan 
Hal senada juga diungkapkan oleh Purnomosidi (2018). Penulis menggunakan suspensi bentonite $350 \mathrm{~cm}^{3}$ dicampur dengan $0.81 \%$ serat eceng gondok.

Gambar 2 merupakan hasil pengamatan $\mathrm{pH}$ terhadap suspensi yang dilakukan untuk mengetahui adanya perubahan $\mathrm{pH}$ akibat perlakuan serat alami di dalam suspensi tersebut.

Di sisi lain, penggunaan asam jawa terhadap suspensi bentonite dengan berbagai konsentrasi akan dapat meningkatkan sifat rheologi suspensi tersebut (Mahto \& Sharma, 2004). Viskositas, yield point and gel strength akan meningkat jika konsentrasi asam jawa dinaikkan sementara air dalam suspensi konstan.

(Ismail dkk., 2015) mengemukakan bahwa penggunaan kulit durian yang digerus dengan berbagai ukuran butir dan konsentrasi terhadap suspensi bentonite, akan menunjukkan adanya peningkatan viskositas plastis.

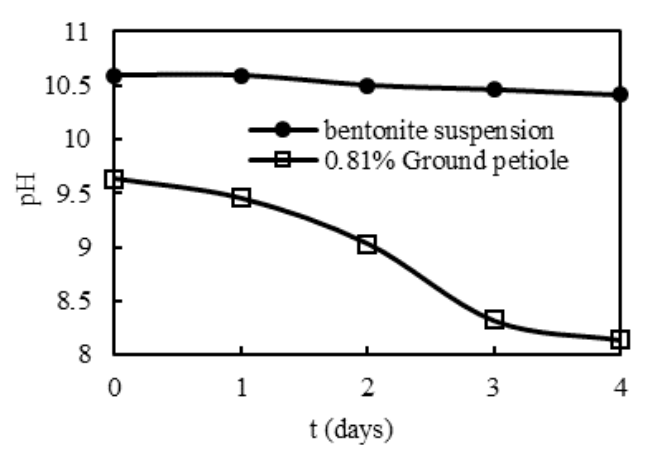

Gambar 2. Hasil pengamatan $\mathrm{pH}$ suspensi bentonite dengan perlakuan $0.81 \%$ serat eceng gondok. (Purnomosidi, 2018).

(Alsabagh dkk., 2015) menggunakan campuran kulit kacang, ampas tebu, dan serbuk gergaji dengan kisaran ukuran partikel antara $3.35 \mathrm{~mm}$ and $0.037 \mathrm{~mm}$ yang dicampur kedalam lumpur pemboran berbahan dasar air. Menurut mereka, kurva shear stress terhadap shear rates mengikuti model Power law untuk fluida non-Newtonian. Lebih lanjut, nilai indeks konsistensi, $\mathrm{n}$, kurang dari 1 berdasarkan percobaan.

Olatunde dkk., (2011) menggunakan getah pohon yang dicampurkan kedalam suspensi bentonite. Kurva konsistensi memberikan kesesuaian dengan model Power law. Lebih lanjut, viskositas, yield point, dan gel strength akan mengalami peningkatan.

Viskositas plastis dan yield point lumpur pemboran yang telah dicampur dengan sekam Psyllium berkonsentrasi $0.75 \%$ hingga $1.0 \%$ akan meningkat dan bersifat seperti model Bingham plastis (Salmachi dkk., 2016).

Bahkan jika pencegahan hilang sirkulasi tidak terlalu efektif, setidaknya keuntungan material hilang sirkulasi tipe serat adalah: membuat jaringan serat yang akan menjaga stabilitas lubang bor (Verret, dkk., 2000), mengurangi biaya penyemenan (Messier dan Morgan, 2003), serta menciptakan mud cake yang tipis, impermeable, untuk menahan laju hilang sirkulasi lanjutan (Taufik, dkk., 2011).

\section{KESIMPULAN}

Selain diharapkan dapat menunjukkan kemampuan menutup zona hilang sirkulasi, secara bersamaan, serat alami juga berpotensi sebagai material aditif tambahan guna perbaikan rheology bagi lumpur pemboran.

Penggunaan beberapa tipe material hilang sirkulasi secara bersamaan dapat memberikan kemampuan penyekatan di zona hilang sirkulasi yang lebih baik. 
Tabel 1. Perilaku LCM jenis serat alami dalam mengatasi hilang sirkulasi (Purnomosidi, 2018)

\begin{tabular}{|c|c|c|c|}
\hline $\begin{array}{c}\text { Drilling fluid } \\
\text { type } \\
\text { (Study) }\end{array}$ & $\begin{array}{l}\text { Conc. } \\
\text { (g/100 } \\
\text { litres) } \\
\end{array}$ & $\begin{array}{l}\text { Fract } \\
\text { size }\end{array}$ & $\begin{array}{c}\text { filtrate } \\
\text { vol.(\%) }\end{array}$ \\
\hline $\begin{array}{l}\text { Tree bark } \\
\text { fibres in } \\
\text { water-based } \\
\text { mud (Nestle, } \\
1948 \text { ) }\end{array}$ & 1880 & $\begin{array}{l}2.7 \\
\mu \mathrm{m}\end{array}$ & 11.5 \\
\hline $\begin{array}{l}\text { Rice residues } \\
\text { in water-based } \\
\text { drilling fluid } \\
\text { (Burts Jr, } \\
\text { 1997) }\end{array}$ & 4270 & $\begin{array}{c}0.4 \text { to } \\
0.8 \\
\mathrm{~mm}\end{array}$ & $\mathrm{n} / \mathrm{a}$ \\
\hline $\begin{array}{l}\text { Coconut } \\
\text { coir in water } \\
\text { (MacQuoid } \\
\text { and Skodack, } \\
\text { 2004) }\end{array}$ & $\begin{array}{c}1420 \text { to } \\
14250\end{array}$ & $\mathrm{n} / \mathrm{a}$ & $\mathrm{n} / \mathrm{a}$ \\
\hline $\begin{array}{l}\text { Grass in } \\
\text { bentonite } \\
\text { suspension } \\
\text { (Hossain and } \\
\text { Wajheeuddin, } \\
\text { 2016) }\end{array}$ & $\begin{array}{c}840 \\
\text { and } \\
1120\end{array}$ & $\begin{array}{l}2.7 \\
\mu \mathrm{m}\end{array}$ & 19 to 25 \\
\hline $\begin{array}{l}\text { Tamarind gum } \\
\text { in bentonite } \\
\text { suspension } \\
\text { (Mahto and } \\
\text { Sharma, 2004) }\end{array}$ & $\begin{array}{c}50 \text { to } \\
250\end{array}$ & $\begin{array}{l}2.7 \\
\mu \mathrm{m}\end{array}$ & $\mathrm{n} / \mathrm{a}$ \\
\hline $\begin{array}{l}\text { Durian rind } \\
\text { in bentonite } \\
\text { suspension } \\
\text { (Ismail, et al., } \\
\text { 2014) }\end{array}$ & 5660 & $\begin{array}{l}\text { up to } \\
3 \mathrm{~mm}\end{array}$ & 16.67 \\
\hline $\begin{array}{l}\text { Sugar cane in } \\
\text { water-based } \\
\text { fluid (Sampey, } \\
\text { 2006) }\end{array}$ & $\begin{array}{l}\text { Up to } \\
4270\end{array}$ & $\begin{array}{l}2.7 \\
\mu \mathrm{m}\end{array}$ & $\mathrm{n} / \mathrm{a}$ \\
\hline $\begin{array}{l}\text { Rice husk } \\
\text { in water } \\
\text { bentonite mud } \\
\text { (Okon, et al., } \\
\text { 2014) }\end{array}$ & 5710 & $\begin{array}{l}2.7 \\
\mu \mathrm{m}\end{array}$ & 64.89 \\
\hline
\end{tabular}

\section{DAFTAR PUSTAKA}

Almagro, S.P.B., Frates, C., Garand, J., and Meyer, A., 2014. Sealing fractures: Advances in lost circulation control treatments. Schlumberger Oilfield Review 2014, 26(3), pp. 4-13.

Alsabagh, A.M., Abdou, M.I., Ahmed, H.E., Khalil, A.A., Aboulrous, A.A., 2015. Evaluation of some natural waterinsoluble cellulosic material as lost circulation control additives in waterbased drilling fluid. Egyptian Journal of Petroleum, 24(4), pp. 461-468.

Alsaba, M., Nygaard, R., Saasen, A., and Nes, O. M., 2014. Lost circulation materials capability of sealing wide fractures. Society of Petroleum Engineers. doi:10.2118/170285-MS.

Annis, M.R. and Smith, M.V., 1996. Drilling Fluids Technology. 1st edn. Texas: Exxon Company.

Burts Jr, B.D., 1997. Lost Circulation Material with Rice Fraction. USA, Patent No. $5,599,776$.

Caskey, B.C., 1985. Lost circulation technology workshop, October 9-10, 1984 (No. SAND-85-0109; CONF8410281-Summ.). Sandia National Labs., Albuquerque, NM (USA).

Droger, N., K., Todd., L., Ellis, C., Salih, O., Silko,N.,Bermudez,R.,2014.Degradable fibre pill for lost circulation in fractured reservoir sections. Society of Petroleum Engineers, doi:10.2118/168024-MS.

Hossain, M.E. and Wajheeuddin, M., 2016. The use of grass as an environmentally friendly additive in water-based drilling fluids. Petroleum Science, 13(2), p. 292- 
303.

Ismail, I., Mohd Nor, A. B., Hamid, F. M. and Ismail, A. R., 2014. The Impact of Durian Rind in Water-based Mud in Combating Lost Circulation. Jurnal Teknologi (Sciences \& Engineering), 74(1), p. 51-56.

Jain, B., Mesa, A. M., Kalbani, S. A., Meyer, A. W., Aghbari, S., Al-Salti, A., Al-Sharji, H. H., 2013. Successful implementation of engineered fibre based loss circulation control solution to effectively cure losses while drilling. Society of Petroleum Engineers, doi:10.2118/166529-MS.

Kefi, S., Lee, J. C., Shindgikar, N. D., BrunetCambus, C., Vidick, B., and Diaz, N. I., 2010. Optimizing in four steps composite lost circulation pills without knowing loss zone width. Society of Petroleum Engineers, doi:10.2118/133735-MS.

Kulkarni, S., Kumar, A., Savari, S., Jamison, D. E., 2012. Novel rheological tool to determine lost circulation materials (LCM) plugging performance. Society of Petroleum Engineers, doi:10.2118/150726-MS.

Kumar, A., Savari, S., Whitfill, D.L., Jamison, D.E., 2014. Wellbore strengthening: A method to evaluate lost circulation materials-investigation of effective wellbore strengthening applications. Society of Petroleum Engineers, doi:10.2118/167977-MS.

Lummus, J.L. and Ryals, J.N., 1971. Preventing loss of drilling fluid to drilled formations. USA, Patent No. 3,629,102.

MacQuoid, M. and Skodack, D., 2004. Method for using coconut coir as a lost circulation material for well drilling. USA, Patent No. US 2004/0129460 A1.

Mahto, V. and Sharma, V. P., 2004. Rheological study of a water-based oil well drilling fluid. Journal of Petroleum Science and Engineering, 45(1-2), pp. 123-128.

Messier, E. and Morgan, D. S.R., 2003. Controlling cement tops through use of fibre-based slurries reduces drilling costs. Petroleum Society of Canada, pp. 15-19.

Nayberg, T. M., 1987. Laboratory study of lost circulation materials for use in both oil-based and water-based drilling muds. Society of petroleum engineers, doi:10.2118/14723-PA.

Nestle, A. C., 1948. Drilling fluid. USA, Patent No. 2,601,050.

Okon, A.N., Udoh, F.D., Bassey, P.G., 2014. Evaluation of rice husk as fluid loss control additive in water-based drilling fluid. Society of Petroleum Engineers, doi:10.2118/172379-MS.

Olatunde, A.O., Usman, M.A., Olafadehan, O.A., Adeosun, T.A. and Ufot, O.E., 2012. Improvement of rheological properties of drilling fluid using locally based materials. Petroleum \& Coal, 54(1).

Priening, P., Ali, M., Jaffery, M., Salazar, J., Jain, B., 2008. Advanced engineered fibre technology- A novel solution to cure lost circulation during drilling: Pakistan case history. Society of Petroleum Engineers, doi:10.2118/114069-MS.

Purnomosidi. 2018. PhD Thesis. Investigating the suitability of biomass Eichhornia 
crassipes as a lost circulation material in water-based drilling muds. University of Aberdeen.

Salmachi, A., Talemi, P., Tooski, Z. Y., 2016. Psyllium husk in water-based drilling fluids: An environmentally friendly viscosity and filtration agent. Society of Petroleum Engineers, doi:10.2118/183308-MS.

Silent, R. A., 1936. Circulation Losses. American Petroleum Institute, pp. 60-66.

Taufik, M., Panjaitan, R.A., Djambek, A., 2011. Fibrous organic cellulose application to combat seepage losses in fractured limestone formations, offshore east Kalimantan, Indonesia. Society of Petroleum Engineers, doi:10.2118/145763-MS.

Verret, R., Robinson, B., Cowan, J., Fader, P., Looney, M., 2000. Use of micronized cellulose fibers to protect producing formations. society of petroleum engineers, doi:10.2118/58794-MS.

White, R. J., 1956. Lost-circulation materials and their evaluation. American Petroleum Institute, pp. 352-359. 